U.S. DEPARTMENT OF THE INTERIOR

U.S. GEOLOGICAL SURVEY

\title{
TOTAL-FIELD AEROMAGNETIC AND DERIVATIVE MAPS OF THE LAWTON AREA, SOUTHWESTERN OKLAHOMA
}

By Meridee Jones-Cecil 